\title{
COMPLEX MODEL OF RISK ASSESSMENT OF INDUSTRIAL PROCESSES MOPORI
}

Modern day society wants to create optimal living conditions for its citizens and to ensure constant sustainable development. This objective cannot be achieved without reaching the required level of perceived security in complex. One of the areas that threaten the lives and property of people and are harmful for the environment is the anthropogenic crisis phenomena, which also include industrial accidents. Prevention of these accidents and subsequent reaction are the key issues considering adjustment of the level of security not only for the citizens of Slovakia, the European Union but also worldwide. The article focuses on the problem of prevention and the way how to deal with the issue in the Slovak Republic as well as on the fulfilment of the requirements in this field which emerge from our membership in the EU. The Faculty of Special Engineering at the University of Zilina deals with partial issues which are necessary to be solved by the approved project APVV - 10 Complex model of risk assessment of industrial processes. Partial results of the project, which is in the second year of its solution, are listed in the text below.

Keywords: Major industrial accidents, prevention, SEVESO directive, risk assessment and treatment, MOPORI, model.

\section{Current state of the problem and the benefits of the outcomes of the project solved}

Several threats both of antropogene or natural character affect people in the current world. And just the industrial accidents which threaten not only people but also the property and the environment belong among these antropogene phenomena. The European Union attempts to control these most dangerous EU enterprises (which have at disposal hazardous substances) through the adaptation of the SEVESO directive. This directive was called after a major industrial accident which happened in an Italian town SEVESO in 1976 [1], [2]. These enterprises are called SEVESO establishments and are classified according to the amount of the hazardous substances to lower tier and upper tier and currently there are approximately 10,000 companies of this type [3]. In spite of all the measures, the major industrial accidents as Bhopal, Schweizerhalle, Enschede, Toulouse and Buncefield claimed even after adopting this directive a lot of lives, damaged the environment and cost the member states lots of millions of EUR [4], [5]. Figs. 1 and 2 show a twelve-year overview according to the classification type and the number of events.

The Slovak Republic as a member of the EU also solves the problem of the major industrial accidents prevention. The basic legal document which transposes directive SEVESO II into our legal environment is Act No.261/2002 Coll. of Laws - law on the prevention of major industrial accidents, as amended, and other two implementing decrees [6].

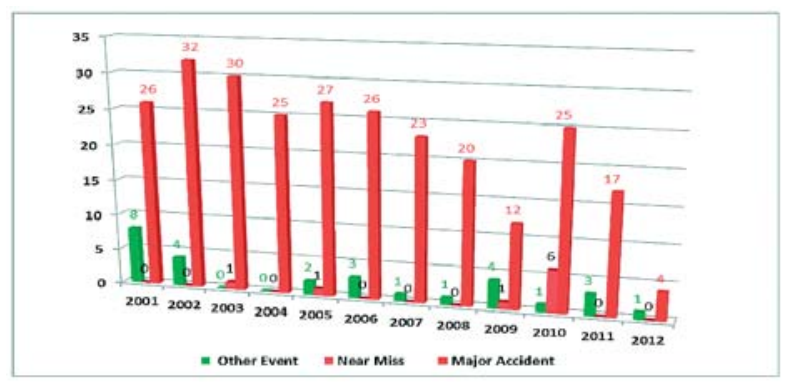

Fig. 1 Events types in eMARS 2001-2012

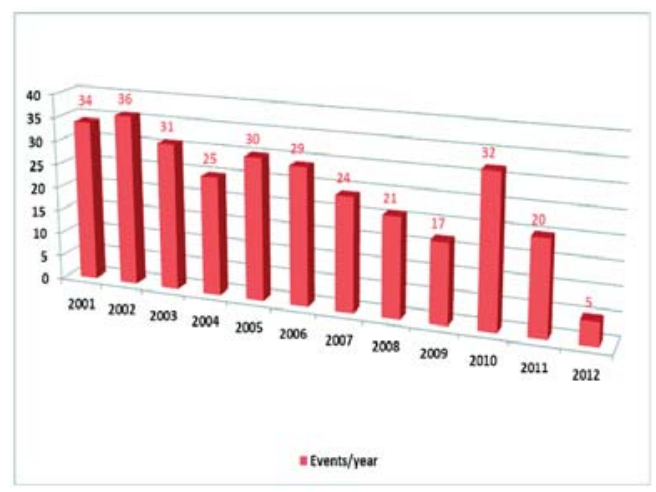

Fig. 2 No. of events 2001- 2012

(Source: https://emars.jrc.ec.europa.eu/)

\footnotetext{
${ }^{*}$ Katarina Holla ${ }^{1}$, Katarina Kampova ${ }^{2}$, Andrea Peterkova ${ }^{1}$, Andrew Collins ${ }^{3}$

${ }^{1}$ Department of Crisis Management, Faculty of Special Engineering, University of Zilina, Slovakia, E-mail: katarina.holla@fsi.uniza.sk

${ }^{2}$ Department of Security Management, University of Zilina, Slovakia

${ }^{3}$ University of Newcastle, Disaster and Development center, United Kingdom
} 
There are several problematic areas in this field. In 2008, The European Virtual Institute for Integrated Risk Management made a questionnaire study, the purpose of which was to obtain information about the transposition requirements of the directive SEVESO II in all the member states. At the same time, it obtained information about and its general advance, practical experience with the use of weaknesses and problems associated with its practical implementation, efficiency of its implementations and its impact on the competitiveness of European industry. Consequently, the member states were asked to react by improving the form of this directive.

The Results of the survey are as follows:

- In some areas, the respondents themselves see the opportunity to elaborate further supporting documents, whereby the point with the highest priority is the area of risk assessment and treat ment.

- The area of concern is non-universality of the risk assessment approach, lack of the criteria to quantify the risks and the methods, tools and data used for implementation of the procedures.

- Many companies elaborate qualitative rather than quantitative analysis, which can conceal a higher level of uncertainty of the results.

- An approach to the risk assessment should be synchronized in accordance with the Directive SEVESO II on the one hand and the legal norms in the field at particular country on the other [7]

Selected findings from the survey indicate insufficient or formal approaches to the risk management within selected enterprises, and thereby confirm the possibility of elimination of the deficiencies by correct, system and mainly live approach of the subjects to the risk assessment and treatment.
As results from the mentioned research, one of the most problematic areas in the sector of the prevention of the major industrial accidents is to assess and treat risks. This issue is not appreciated by the laic general public as well as by the expert public at the time when there is no accident in a long-term. However, in case it occurs, the loss of human lives and material values prove to everyone that the issues related to the prevention of this type of accidents are necessary. It is also necessary to address number of demands related to dysfunction of the risk management system in a given subject. These dysfunctions could occur either due to poor coordination of particular activities within the prevention or by inappropriate reaction to the resulting accident. The causes of these types of accident are various and in most of the cases it is possible to talk about formally elaborated system of risk assessment and treatment. It means that the complex interconnection is not secured considering the system, organizational, personal, technical or material aspects [3]

It is just this crucial topic of assessment and treatment of risks which is the main problem being solved within the project APVV 0043 - 10 Complex model of risk assessment of industrial processes

\section{Resources and results of the Project APVV 0043 - 10 Complex Model of Risk Assessment of Industrial Processes}

Project with the title "Complex Model of Risk Assessment of Industrial Processes" (thereinafter MOPORI) originated due to the requirements to create a simple and system approach to risk assessment and management. The main objective of the project is to increase a security level of industrial enterprises - "Seveso establishments" in the Slovak Republic by creating a complex model of

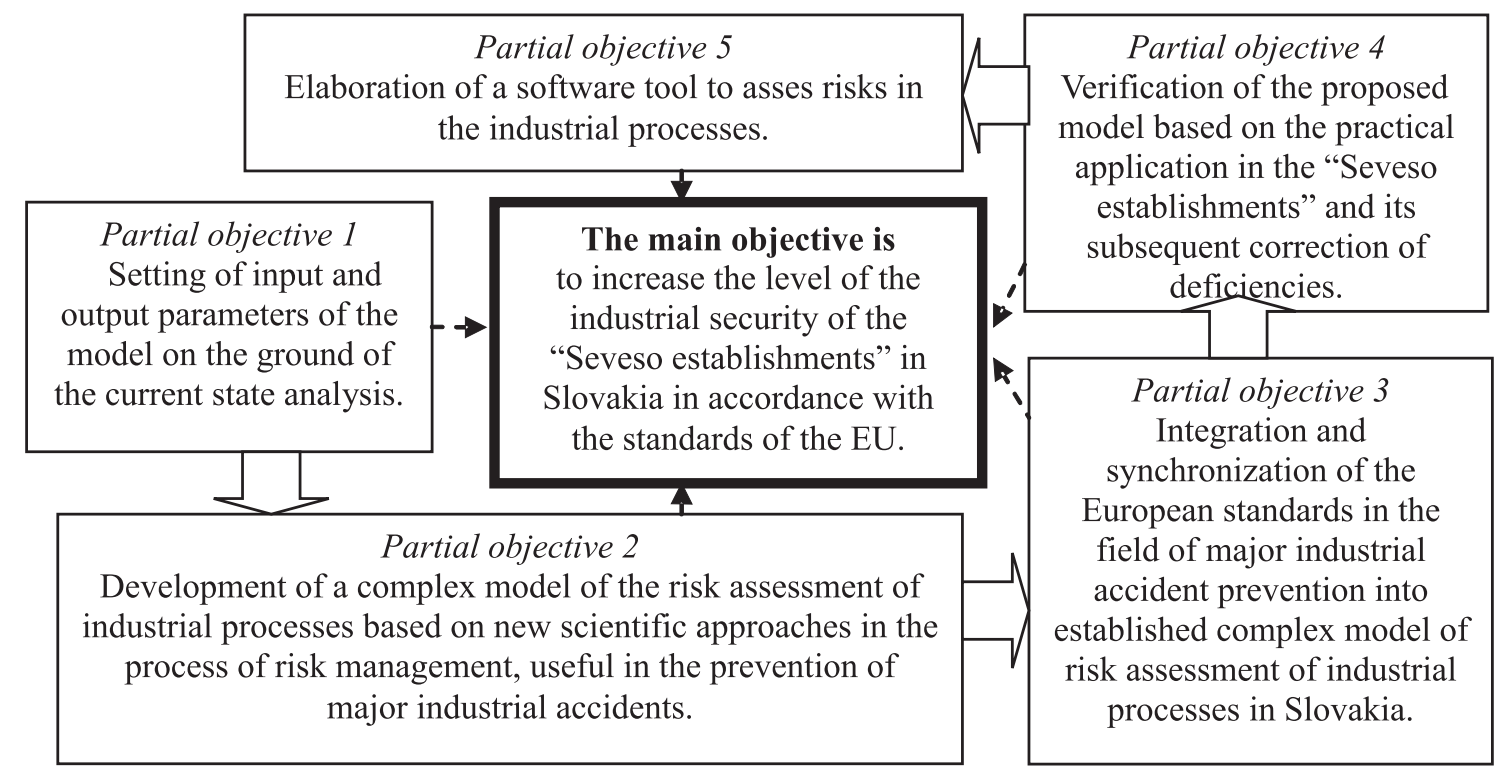

Fig. 3 The main objective and the partial objectives of the project 
risk assessment of industrial processes with the use of quantitative methods and by its synchronization with the standards of the EU and their subsequent application in Slovakian conditions.

Duration of the project "MOPORI" is in the time interval $5 / 2011-4 / 2014$. Throughout its duration, the project was given the main objective as well as the partial objectives whose interaction can be seen in Fig. 3 .

Accomplishment of the main declared objective of the project MOPORI is ensured by creating eight work packages [8], which are designed in accordance with the general project and implementing phases of the project management. The titles of the work packages are listed below:

- PB0 Management of the project

- PB1 Complex analysis of the current state of the problem solved

- PB2 Development of a complex model of the risk assessment of industrial processes

- PB3 Application of the European standards in the field of major industrial accident prevention into the complex model of the risk assessment of industrial processes in Slovakian conditions

- PB4 Verification of the complex model of the risk assessment of industrial processes in practice

- PB5 Elaboration of a software tool to assess the risks of the industrial processes in Slovakian conditions

- PB6 Popularization of the project results

- PB7 Use of the project results

To support the project solution in addition to the clearly set work packages and activities, a council of experts has been nominated within the packages that composes of the representatives of selected target groups, namely:

- "Seveso establishments".

- Assessors: RISK CONSULT, s.r.o. (Ing. Jan Kandrac, CSc., Ing. Marek Kandrac - experts for prevention of major industrial accidents).

- Evaluators: Representatives of the Ministry of Environment of SR - Department of environmental risks and biosafety.

\section{Results achieved within the time horizon of the project MOPORI}

The above-described main objective of the project MOPORI - increase of the security level of industrial enterprises - "Seveso establishments" in $S R$, is achieved within the project by completion of the partial objectives which create conditions for its fulfilment. Partial objectives are met by the project team that is comprised of experts from the practice and scientific researchers from the $\mathrm{ZU}$. Currently, it is possible to present these partial outputs from the individual defined work packages as follows:

The first partial objective "Setting of input and output parameters of the model on the ground of the current state analysis" creates conditions to fulfil another objective to design a model of risk assessment of the industrial processes by means of:

- Needs analysis following the lessons learnt from the major industrial accidents prevention in SR and EU.
- Analysis and synthesis of the conclusions of the survey performed among the SEVESO establishments.

- Stakeholders' workshops.

The table listed below presents an overview of the major industrial accidents in the time period 2003-2011. The importance of this overview is in the analysis "lessons learnt" from these unwanted events. This analysis also created one of the assumptions to define input and output parameters of the proposed model in the partial objective 2 .

Based on the analysis of major industrial accidents (see Table 1) main causes of this type of event were identified.

The analysis "lessons learnt" was subsequently amended by the survey which focused on the issues of major industrial accidents and the fulfilment of the requirements valid for the SEVESO establishments in the Slovak Republic with an emphasis on the implementation of the risk assessment and treatment. The questionnaire was sent to all SEVESO establishments in Slovakia (80) while the backflow was more than $50 \%$. The project team considers this backflow as a success which was conditioned by the long-term and intensive communication not only of the project team from the university environment but also by the use of contacts from the institutions involved in the project MOPORI. Based on a survey conducted by the questionnaire method several facts were detected out of which we choose the most important and relevant to the proposed model:

- Inconsistency of the used approaches and methods of risk assessment and treatment of industrial processes whereby there is missing possibility to compare results (different algorithms of the approaches based on the economic potential of the subject).

- Inadequate conditions for the application of the quantitative procedures for the risk assessment and treatment.

- The lack of explanatory documents and methodologies for processing the required source data necessary for the documentation in question.

- Inconsistency in an approach to assess risks of the natural character considering the ambiguity of data and criteria for their assessment.

- The lack of knowledge on new approaches to the latest technical and technological development in the field of major industrial accident prevention.

Another approach to achieve this objective was a personal contact with selected stakeholders, which was arranged during the created workshops. In the workshops, creation of the model and the definition of the input and output parameters were the primarily addressed issues. The added value of these workshops was to identify perspectives on the problem solved form various points of view. The Ministry of Environment as a competent authority sees the main problem in the quality of the elaborated documents submitted by the SEVESO establishments. Processors of the security documentation, whether internal or external, do not have required qualification, experience and frequently they are given incomplete materials form the SEVESO establishments. The outcomes of the workshops were processed as a ground for creation of a model of 


\section{COMMNICOIIONS}

Major industrial accidents in the Slovak Republic in the time period 2003 - 2011 [9]

Table 1

\begin{tabular}{|c|c|c|c|}
\hline Name of the enterprise & Date of the event & Place and type of the event & Cause \\
\hline DUSLO, a.s. & 24.7 .2010 & $\begin{array}{c}\text { Office building (production of ammonia) } \\
\text { 1236, Sala technical failure, explosion, fire }\end{array}$ & $\begin{array}{c}\text { Flange leak on a high pressure synthesis } \\
\text { gas distribution }\end{array}$ \\
\hline $\begin{array}{c}\text { Novacke chemicke } \\
\text { zavody, a.s. }\end{array}$ & 28.9 .2005 & $\begin{array}{c}\text { Novaky, company area, ethylenehydrin } \\
\text { operation, human error }\end{array}$ & $\begin{array}{c}\text { Welding and ignition of the explosive blend from } \\
\text { the weld joint }\end{array}$ \\
\hline $\begin{array}{c}\text { U. S. Steel } \\
\text { Kosice, s. r. o. }\end{array}$ & 28.9 .2005 & $\begin{array}{c}\text { The energy division, energy media } \\
\text { operation, technical failure, explosion, fire }\end{array}$ & $\begin{array}{c}\text { Damage and subsequent breakage of the end } \\
\text { of the shaft inside the wheel of the centrifugal pump } \\
\text { type A-CB 185/4-7,2 Nr. 1. }\end{array}$ \\
\hline $\begin{array}{c}\text { U. S. Steel } \\
\text { Kosice, s. r. o. }\end{array}$ & 16.11 .2006 & Company area - technical failure & $\begin{array}{c}\text { Power failure and subsequent failure of technological } \\
\text { and security equipment of the company }\end{array}$ \\
\hline
\end{tabular}

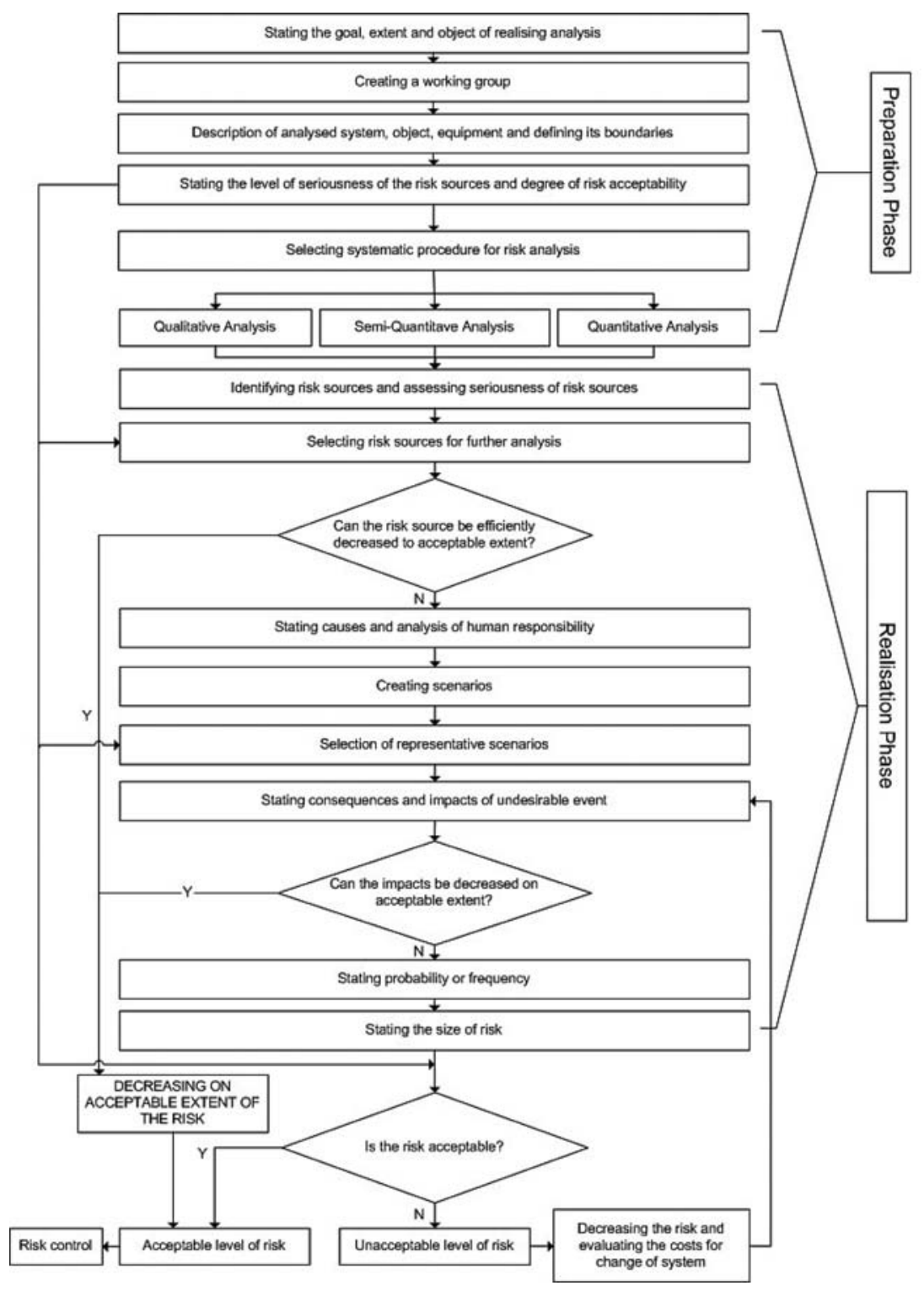

Fig. 4 Model of risk assessment of industrial processes 
risks assessment and treatment of industrial processes, and together with the individual contributions from the participating stakeholders they were compiled in an electronic anthology that was published on $\mathrm{CD}$. The project website is the main dissemination channel to spread the results of the workshops.

The three basic approaches (analysis of lessons learnt, questionnaire survey and stakeholders workshops) contributed to the solution of the partial objective "Setting of input and output parameters of the model on the ground of the current state analysis" and created a primary source of information for the design of the model, which forms the main output of another project objective "Development of a complex model of the risk assessment of industrial processes based on new scientific approaches in the process of risk management useful in the major industrial accidents prevention".

Based on the observed assumptions and analysis of the approaches currently in use as well as of the modern ones a model of risk assessment of industrial processes has been proposed and designed which will be verified by practical application in two of the "Seveso establishments". The verification of the accuracy of the proposed model is planned for the next year of the project. The verification should enable the incorporation of the deficiencies of the designed model so that the proposed model could be correct from the viewpoint of the usability by the stakeholders. Consequently, an efficient software tool to assess the risks in industrial processes could be created. This tool should remedy the deficiencies associated with the errors in assessment and management of risks that has been partially described in this article.

The model shown in Fig. 4 was created as a basic algorithm for risk assessment and management in the field of major industrial accident prevention within this project and is also useful for other types of accidents in industrial plants. Formalizing the approaches and pointing out the link between individual phases and steps of the created model is one of the key positives of the model $[9,10]$.

\section{Plans for the future within MOPORI}

Considering the continuation of the project, the project team has defined the essential activities and tasks associated with the fulfilment of the defined partial objectives of the project, namely: Based on the established model of risk assessment of industrial processes, an integration of currently valid as well as newly-formed approaches in the project will be implemented to achieve its complexity. Two representative models will be established, one will have a character of a deterministic approach and the other of a probabilistic approach [11].

Established model and the application of the currently valid approaches and methods into particular phases and steps will create a prerequisite for its verification in two of the SEVESO establishments. Negotiations are currently underway with several companies. The model will be applied into use by two experts for major industrial accidents prevention from the University of Zilina and two employees of the company Risk Consult who are involved in the project. Due to the use of two different approaches within the model, it will be possible to compare the results of the application not only between the companies but also between the different approaches established. Based on this, new conclusions will be determined and so will, consequently, advantages and disadvantages of the application of the complex model.

The next planned step is to create a software tool for risk assessment in the industrial processes. Following the verification of the model in practice, deficiencies of the complex model will be eliminated and a software tool will be created and recommended for use by the companies in the Slovak Republic $[12,13]$.

\section{Conclusion}

In addition to the main outputs that have been mentioned above, the project team produces other outputs while achieving the partial objectives of the project. The main ones include dissemination activities on conferences within the Slovak Republic, the European Union but also in the USA or Canada. Next year, the first monograph will be published in the field of the problem solved with the title "Prevention of major industrial accident" necessary to improve the learning process on the issues in question at the FSI. In like manner, the finances of the project are also used to increase the competences of individual members of the research team - to become a proficient specialist to prevent major industrial accidents, an emergency technician or an OSH technician. In addition to these results, this year a new project was submitted to 7Framework programme SEC-2013-1 with a title Industrial Accidents Prevention Stakeholders Platform - INFORM. More information on the activities of the project is available on the project website http://mopori.blogspot.sk/.

\section{Acknowledgements}

This work was supported by the Slovak Research and Development Agency under the contract No. APVV-0043-10.

\section{References}

[1] SEVESO II 96/82/EC, European Commission, Technical Working Group (TWG) of representatives from the Commission and from Member States, 1996, [on line] [cit. 2011-8-8]. Available on http://mahb.jrc.it/fileadmin/MAHB/downloads/guidance/id27/Twg6-en.pdf

[2] SEVESO 82/501/EEC, The Council of the European Communities, 1982, [on line] [cit. 2011-8-8]. Available on http://www.ess.co.at/HITERM/REGULATIONS/82-501-eec.html 
[3] MALindZaKoVA, M. FUTO, J.: Tunnel Boring Machine Design and Reliability Parameters of a Dynamic Rock-indentor System. Communications - Scientific Letters of the University of Zilina, vol. 14, Nr. 4, 2012, p. 79-82. ISSN 1335-4205.

[4] ZANICKA HOLLA, K., RISTVEJ, J., SIMAK, L.: Risk Assessment in Industrial Processes. Iura Edition, spol. s. r. o., 2010, ISBN 978-80-8078-344-0, Bratislava

[5] ZANICKA HOLLA, K., MORICOVA, V.: Human Factor Position in Rise and Demonstration of Accidents, Communications Scientific Letters of the University of Zilina, ISSN 1335-4205, vol. 13, Nr. 2, 2011, p. 49-52.

[6] SEVESO II 2003/105/ EC, European Commission, European parliament and of the council, 2003, [on line] [cit. 2011-8-8]. Available on http://eur-lex.europa.eu/LexUriServ/LexUriServ.do?uri=DD:05:04:32003L0105:SK:PDF

[7] SALVI, O. et al: F - SEVESO. Study of the Effectiveness of the Seveso II directive, 2008. Brusel : EU - Vri.

[8] KORMANCOVA, G.: Software Support of Project Management, On-line journal: Manazment v teorii a praxi, vol. 6, Nr. 1, 2010. ISSN 1336-7137; On-line available: http://casopisy.euke.sk/mtp/clanky/1-2010/mtp1-2010.pdf.

[9] RISTVEJ, J., ZAGORECKI, A.: Information Systems for Crisis Management - Current Applications and Future Directions, Communications - Scientific Letters of the University of Zilina, vol. 13, Nr. 2, 2011, p. 59-63, ISSN: 1335-4205.

[10] LOVECEK, T.: Present and Future Ways of Physical Property Protection. Communications - Scientific Letters of the University of Zilina, vol. 10, Nr. 1, 2008, pp. 35-39.

[11] KAMPOVA, K.: Foundations of Implementation of Risk Management Process within Project Management, Communications Scientific Letters of the University of Zilina, vol. 13, Nr. 2, 2011, pp. 88-91, ISSN 1335-4205.

[12] SIMAK, L.: Increasing the Security Level in the Slovak Republic, Communications - Scientific Letters of the University of Zilina, vol. 10, No. 2, 2018, pp. 67-71, ISSN 1335-4205

[13] SVENTEKOVA, E., DVORAK, Z.: Human Activity as a Risk in Railway Transport, Transport Means - Proc. of the Intern. Conference, 2011, pp. 50-53. 